\title{
Isolation of Neisseria lactamicus from the nasopharynx
}

\author{
ANGELA H. PYKETT \\ From the Public Health Laboratory, Withington Hospital, Manchester
}

SYNOPSIS During 1971 and 1972, 71 cultures of neisseriae that attacked lactose were received by this laboratory. All strains except one from an eye swab were from the nasopharynx of healthy subjects. Nineteen similar strains from the nasopharynx were isolated in this laboratory.

The characteristics of these strains were compared with those of Neisseria meningitidis, Neisseria pharyngis, Neisseria catarrhalis, and Neisseria lactamicus. The 90 strains under investigation closely resembled Neisseria meningitidis but could be differentiated by production of acid from lactose and beta-galactosidase activity and were therefore classified as Neisseria lactamicus.

Amongst cultures of presumptive meningococci sent to this laboratory in 1971 and 1972 for typing, we have identified 71 cultures of neisseriae that attacked lactose. Nineteen similar strains were isolated in this laboratory. All strains except one from an eye swab were isolated from the nasopharynx of healthy subjects during the course of meningococcal carrier surveys or as a follow up of contacts of cases of meningococcal infection. All nasopharyngeal strains were isolated initially on selective medium (Thayer and Martin, 1966). The characteristics of these 90 strains were compared with those of $N$. meningitidis and a number of commensal neisseriae.

\section{Materials and Methods}

Ninety strains of lactose-positive neisseriae detailed above, three strains each of $N$. meningitidis types $\mathrm{A}$ and $\mathrm{B}$, one strain of $N$. meningitidis type $\mathrm{C}$, three strains of $N$. pharyngis, and seven strains of $N$. catarrhalis were studied. All these strains had been isolated in this laboratory or received here during the past two years and preserved on Dorset egg slopes at $30^{\circ} \mathrm{C}$.

In addition, a number of freeze-dried cultures were examined: three strains of $N$. lactamicus (NCTC 10616, 10617, and 10618), N. catarrhalis (NCTC 3622), $N$. pharyngis (NCTC 4590 and 4591), and type strains of $N$. meningitidis types $\mathrm{A}, \mathrm{B}$, and $\mathrm{C}$ (M 1027, $M 993$, and M 1628) originally obtained from Sara Branham.

A proportion of strains were tested for growth at 37 and $25^{\circ} \mathrm{C}$. Two media were used: $10 \%$ horse Received for publication 10 April 1973. blood agar (Oxoid CM 271) and nutrient agar (Oxoid CM 3). Incubation was carried out both aerobically and in a candle jar for five days.

Acid production from four carbohydratesglucose, maltose, sucrose, and lactose-was tested, using BBL cystine trypticase (no. 01-174) agar slopes, with $1 \%$ added carbohydrate. Slopes were incubated aerobically at $37^{\circ} \mathrm{C}$ for seven days before the final reading.

Beta-galactosidase activity was tested by the method of Lowe (1962) modified by substituting Difco Mueller-Hinton broth for peptone water. A heavy inoculum was used and results read after three and 24 hours' incubation at $37^{\circ} \mathrm{C}$.

Serotyping was carried out by the agglutination method of Slaterus (1962) using antisera to Neisseria meningitidis types $\mathrm{A}, \mathrm{B}, \mathrm{C}, \mathrm{X}, \mathrm{Y}$, and $\mathrm{Z}$.

\section{Results}

All strains were oxidase-positive, Gram-negative diplococci. Colonies of the lactose-positive strains and those of the three NCTC strains of N. lactamicus were often indistinguishable from those of $N$. meningitidis. Strains of $N$. catarrhalis and $N$. pharyngis all grew well on nutrient agar at $25^{\circ} \mathrm{C}$. Growth of the lactose-positive strains and $N$. meningitidis at this temperature was variable according to the strain tested; some lactose-positive strains and some strains of $N$. meningitidis produced growth when a heavy inoculum was used and incubation carried out in a candle jar.

Acid production from carbohydrates was as shown in the table. 


\begin{tabular}{|c|c|c|c|c|c|c|}
\hline \multirow[t]{2}{*}{ Strain } & \multirow[t]{2}{*}{ No. Tested } & \multicolumn{5}{|c|}{ Action on Carbohydrates ${ }^{1}$} \\
\hline & & Glucose & Maltose & Sucrose & Lactose & $O N P G$ \\
\hline N. catarrhalis & 8 & - & - & - & - & - \\
\hline$N$. pharyngis & 5 & : &. & . & - & - \\
\hline N. meningitidis & 10 & 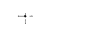 & + & - & - & - \\
\hline N. lactamicus (NCTC strains) & 3 & + & + & - & t & + \\
\hline Lactose-positive strains & 90 & + & + & - & + & + \\
\hline
\end{tabular}

Table Distinguishing biochemical reactions of neisseria strains tested

$1_{i}=$ positive, acid produced, $-=$ negative, no acid produced

The NCTC strains of $N$. lactamicus and the lactose-positive strains under investigation consistently fermented lactose, usually within $\mathbf{4 8}$ hours, and showed beta-galactosidase activity. No other strains tested fermented lactose or gave a positive ONPG.

All the lactose-positive strains and the three NCTC strains of $N$. lactamicus were untypable with antisera to $N$. meningitidis types $\mathrm{A}, \mathrm{B}, \mathrm{C}, \mathrm{X}, \mathrm{Y}$ and $\mathrm{Z}$ and more than $50 \%$ were autoagglutinable.

\section{Discussion}

Production of acid from lactose and beta-galactosidase activity are characteristic of $N$. lactamicus (Mitchell, Rhoden, and King, 1965; Hollis, Wiggins, and Weaver, 1969). The strains under investigation also showed these properties and were therefore classified as $N$. lactamicus. Morphologically and in its action on other carbohydrates, this organism may be indistinguishable from $N$. meningitidis. Weiss, Wilson, Schramek, and Hill (1971) found that the DNA of $N$. lactamicus showed partial reassociation with the DNA of $N$. meningitidis (75 to $56 \%$ ) and more extensive but variable degrees of reassociation with other strains of $N$. lactamicus ( 98 to $72 \%$ ). They suggest that $N$. lactamicus can be distinguished from $N$. meningitidis on the basis of DNA reassociation.

$N$. lactamicus is frequently isolated in carrier studies. Jephcott and Morton (1972) have recently described the isolation of this organism from a cervical swab. As the clinical significance of $N$. lactamicus has not yet been established, it is important to distinguish it from $N$. meningitidis. Acid production from lactose and beta-galactosidase activity by the ONPG reaction are the most useful means of identifying $N$. lactamicus (Hollis et al, 1969).

I am grateful to Dr S. P. Lapage for the NCTC strains and to Dr P. K. Fraser for a number of strains of Neisseria lactamicus.

References

Hollis, D. G., Wiggins, G. L., and Weaver, R. E. (1969). Neisseria lactamicus sp. n., a lactose-fermenting species resembling Neisseria meningitidis. Appl. Microbiol., 17, 71-77.

Jephcott, A. E., and Morton, R. S. (1972). Isolation of Neisseria lactamicus from a genital site. Lancet, 2, 739-740.

Lowe, G. H. (1962). The rapid detection of lactose fermentation in paracolon organisms by the demonstration of $\beta$-galactosidase. J. med. Lab. Technol., 19, 21.

Mitchell, M. S., Rhoden, D. L., and King, E. O. (1965). Lactosefermenting organisms resembling Neisseria meningitidis. $J$. Bact., 90, 560 .

Slaterus, K. W. (1962). Over de epidemiologie van de meningococcen infectie. Thesis, University of Amsterdam, pp. 32-35.

Thayer, J. D., and Martin, J. E. (1966). Improved medium selective for the cultivation of Neisseria gonorrhoeae and Neisseria meningitidis. Publ. Hlth Rep. (Wash.), 81, 559-562.

Weiss, E., Wilson, N. N., Schramek, S., and Hill, J. C. (1971). Partial reassociation between the dexoxyribonucleic acids of Neisseria lactamicus and Neisseria meningitidis. Infect. and Immun., 3 274-277. 